\title{
Análise de intervenção intersetorial na prevenção à violência sexual na primeira
}

\section{infância}

\author{
Analysis of intersectoral intervention in preventing sexual violence in early childhood \\ Análisis de la intervención intersectorial para prevenir la violencia sexual en la primera infancia
}

Recebido: 26/01/2021 | Revisado: 01/02/2021 | Aceito: 02/02/2021 | Publicado: 08/02/2021

Nariana Rodrigues de Freitas

ORCID: https://orcid.org/0000-0002-2283-9945

Prefeitura Municipal de São José dos Pinhais, Brasil

E-mail: nariana@gmail.com

Paula Romite

ORCID: https://orcid.org/0000-0001-6069-4348

Prefeitura Municipal de São José dos Pinhais, Brasil E-mail: paularomite@gmail.com

\begin{abstract}
Resumo
O respectivo artigo apresenta o resultado da análise da prática interventiva do Centro de Referência Especializado de Assistência Social (CREAS) de São José dos Pinhais/PR em atuação intersetorial na prevenção da violência sexual na primeira infância. $\mathrm{O}$ objetivo é avaliar o projeto de prevenção à violência sexual infantil, considerando a análise dos profissionais que participaram do processo de capacitação. A intervenção foi realizada por meio de um projeto de capacitação a profissionais da rede de educação com o intuito de fornecer conteúdos e esclarecimentos sobre o abuso sexual na primeira infância e subsidiar tratativas instrumentais necessárias ao trabalho de prevenção dessa violência junto às crianças e seus responsáveis no âmbito escolar. Por meio da análise qualitativa realizada com dados extraídos de questionários aplicados nas capacitações, tal estudo apontou a relevância do trabalho intersetorial na prevenção às situações de violência sexual na primeira infância, um fenômeno multidimensional, assim como suas consequências.

Palavras-chave: Violência sexual; Primeira infância; Prevenção; Intervenção intersetorial; Âmbito escolar.
\end{abstract}

\begin{abstract}
The respective article presents the result of the analysis of the interventional practice of the Specialized Reference Center for Social Assistance (CREAS) of São José dos Pinhais/PR in intersectoral action in the prevention of sexual violence in early childhood. The objective is to evaluate the project to prevent child sexual violence, considering the analysis of the professionals who participated in the training process. The intervention was carried out through a training project for professionals in the education network in order to provide content and clarification on sexual abuse in early childhood and to support instrumental treatments necessary to prevent violence against children and their parents. school setting. Through the qualitative analysis carried out with data extracted from questionnaires applied in the training, this study pointed out the relevance of intersectoral work in preventing situations of sexual violence in early childhood, a multidimensional phenomenon, as well as its consequences.
\end{abstract}

Keywords: Sexual violence; Early childhood; Prevention; Intersectoral intervention; School setting.

\section{Resumen}

El artículo respectivo presenta el resultado del análisis de la práctica intervencionista del Centro de Referencia Especializado de Asistencia Social (CREAS) de São José dos Pinhais/PR en la acción intersectorial en la prevención de la violencia sexual en la primera infancia. El objetivo es evaluar el proyecto de prevención de la violencia sexual infantil, considerando el análisis de los profesionales que participaron en el proceso de formación. La intervención se llevó a cabo a través de un proyecto de formación de profesionales de la red educativa con el fin de brindar contenido y esclarecimiento sobre el abuso sexual en la primera infancia y apoyar los tratamientos instrumentales necesarios para prevenir la violencia contra los niños y sus padres. entorno escolar. A través del análisis cualitativo realizado con datos extraídos de cuestionarios aplicados en la formación, este estudio señaló la relevancia del trabajo intersectorial en la prevención de situaciones de violencia sexual en la primera infancia, fenómeno multidimensional, así como sus consecuencias.

Palabras clave: Violencia sexual; Primera infancia; Prevención; Intervención intersectorial; Entorno escolar. 


\section{Introdução}

A violência contra a criança infelizmente faz parte da trajetória cultural antiga da sociedade, no entanto a garantia de proteção integral é uma conquista recente na legislação nacional. Diversas são as modalidades de violência infantil, porém, para o propósito deste artigo, será abordada a violência sexual ocorrida na primeira infância, ou seja, conforme o Art. $2^{\circ}$ da Lei n. 13.257, "período que abrange os primeiros 6 (seis) anos completos ou 72 (setenta e dois) meses de vida da criança" (Brasil, 2016).

Na primeira infância, a socialização intrafamiliar é intrínseca ao processo de desenvolvimento psicossocial infantil. No entanto, a família nem sempre garante a proteção e os meios necessários para o desenvolvimento saudável da criança. Ainda, a primeira infância representa o início da socialização por meio da inserção nas instituições escolares, nesse sentido, considerouse, neste estudo, a escola como um local privilegiado para identificar, denunciar e prevenir as situações de violência sexual na primeira infância.

Diante da complexidade que envolve as situações de violência, especificamente a violência sexual infantil na primeira infância, e dos prejuízos que tal violação pode gerar a vítima, percebe-se a urgência de investir em intervenções preventivas articuladas com diversos atores da rede de proteção, a fim de garantir a proteção integral das crianças, conforme preconiza o Estatuto da Criança e do Adolescente - ECA (Lei n. 8.069 de 1990).

Desta forma, a equipe técnica do Centro de Referência Especializado da Assistência Social - CREAS do município de São José dos Pinhais/PR identificou a demanda supracitada e elaborou um projeto de prevenção ao abuso sexual infantil, planejado e executado de forma intersetorial entre profissionais da política de Assistência Social, Saúde e Educação.

O projeto de prevenção à violência sexual infantil na primeira infância foi executado no ano de 2018 e incluiu a capacitação de profissionais da educação, com o objetivo de fornecer conhecimento e ferramentas práticas para que pudessem multiplicar o conhecimento com os pais e alunos no âmbito escolar.

Sendo assim, o foco desta pesquisa é avaliar o projeto de prevenção à violência sexual infantil executado pela equipe do CREAS de São José dos Pinhais/PR, considerando a análise dos profissionais que participaram do processo de capacitação.

Nesse contexto, o presente estudo contribui para a discussão da relevância do desenvolvimento de trabalhos de prevenção à violência sexual infantil na primeira infância, por meio da articulação intersetorial.

\section{Violência Sexual Infantil e as Políticas Públicas}

A violência contra a criança faz parte da história da humanidade, sendo por vezes naturalizada pela sua trajetória cultural, deixando marcas profundas até os dias atuais. No decorrer da história, diversos foram os avanços legais em relação à proteção das crianças até a promulgação da Constituição Federal de 1988 e o Estatuto da Criança e do Adolescente, de 1990.

O Estatuto da Criança e do Adolescente (ECA) expõe que nenhuma criança ou adolescente deve ser objeto de qualquer forma de violência e responsabiliza diferentes atores para garantir a proteção integral de crianças e adolescentes.

Diversos são os tipos de violência contra crianças, tais como violência física, psicológica e negligência. Em relação à violência sexual infantil, foco deste estudo, é considerada pela Organização Mundial da Saúde (OMS) como:

O envolvimento de uma criança em atividade sexual que ele ou ela não compreende completamente, é incapaz de consentir, ou para a qual, em função de seu desenvolvimento, a criança não está preparada e não pode consentir, ou que viole as leis ou tabus da sociedade. (World Health Organization, 1999, p. 7).

Quando identificada a violação de direitos à criança, o Conselho Tutelar, órgão permanente e autônomo que zela pelos direitos das crianças, deve aplicar as medidas de proteção expressas no Estatuto da Criança e do Adolescente. Dentre as medidas 
protetivas previstas está representada pela Lei n. 8.069 em seu Art. 101, que estabelece "orientação, apoio e acompanhamento temporários" (Brasil, 1990), sendo essa medida executada no CREAS junto às famílias.

O trabalho desenvolvido com as famílias como medida de proteção aplicada pelo Conselho Tutelar ao CREAS tem o objetivo de orientá-las em relação ao seu papel protetor e contribui para o rompimento dos padrões violadores de direitos.

Contudo, a equipe técnica do CREAS observou no exercício da prática profissional que as intervenções em relação às situações de violência sexual na primeira infância eram limitadas, visto que o abuso sexual já havia ocorrido e a família e a vítima enfrentavam as consequências decorrentes dessa violência. Nesse sentido, foi observada a necessidade urgente de expandir o trabalho em caráter preventivo.

\section{Articulação Intersetorial e Prevenção da Violência Infantil no Ambiente Escolar}

De acordo com as Orientações Técnicas do CREAS (2011), as intervenções de trabalho que envolvem situações de violações de direitos são dinâmicas, complexas e multifacetadas. Nesse sentido, considera-se a necessidade da articulação com a rede de proteção para qualificar a atenção às famílias. Essa articulação tem como objetivo integrar os diferentes agentes das políticas sociais e intersetoriais, podendo ser compreendido como "um processo que cria e mantém conexões entre diferentes organizações, a partir da compreensão do seu funcionamento, dinâmicas e papel desempenhado, de modo a coordenar interesses distintos e fortalecer os comuns" (MDS, 2009, p. 21).

Compreendendo a complexidade das violações de direitos contra crianças, além da responsabilidade de todos os atores da sociedade civil em zelar pela proteção delas, é fundamental adotar estratégias de intervenções capazes de atender a demanda da violência de forma qualificada, prezando pelo trabalho de prevenção. "Nessa direção, destacam-se, inclusive, as ações de intervenção no território, voltadas à prevenção e ao enfrentamento de situações de risco pessoal e social, por violação de direitos" (MDS, 2011, p.12).

Sendo assim, considerando o território como local estratégico para intervenções em situações de violência, é perceptível que o ambiente escolar seja adequado para executar um projeto preventivo eficaz, pois no cotidiano das crianças é possível identificar situações de violência e garantir a devida proteção por meio da prevenção. Podemos constatar essa afirmação, visto que:

A escola é o primeiro espaço de atuação pública da criança, na qual ela vai interagir com outras pessoas e manifestar sua identidade pessoal. [...] o que falta é descobrir os caminhos capazes de modificar ou interferir com algumas ações para diminuir a violência, a indisciplina e a agressividade presentes nas escolas. (Ribeiro \& Martins, 2011, p. 25).

Diante da necessidade do trabalho preventivo à violência sexual infantil, as diretrizes da Política Nacional de Educação Infantil respaldam o trabalho interdisciplinar entre o CREAS e as Instituições de Ensino quando apontam que esta deve articularse com os órgãos e equipamentos necessários "para assegurar, nas instituições, o atendimento integral à criança considerando os seus aspectos físico, afetivo, cognitivo/linguístico, sociocultural, bem como as dimensões lúdica, artística e imaginária” (Brasil, 2004).

Considerando as legislações que expõem o trabalho de prevenção às situações de violações de direitos, o projeto de prevenção do CREAS de São José dos Pinhais/PR tem como objetivo a contribuição ao processo de rompimento às situações de violência sexual na primeira infância. 


\section{Projeto de Prevenção e Capacitação}

A fim de contextualizar a construção do projeto de prevenção, ressalta-se que o trabalho foi desenvolvido originalmente pelos profissionais do CREAS de São José dos Pinhais/PR para intervenção grupal com as famílias em acompanhamento coma intenção de fortalecer o papel protetor destas, bem como orientar sobre as consequências da violência sexual infantil, desmistificando os pensamentos do senso comum.

Ao avaliar a relevância do projeto, sua aplicação foi ampliada com o propósito preventivo por meio de encontros grupais com as crianças no ambiente escolar, visando a promoção de informações sobre a autoproteção e o compartilhamento de orientações preventivas aos pais.

Posteriormente, os profissionais do CREAS perceberam a viabilidade de capacitar os profissionais da rede de ensino com o intuito de que se tornassem multiplicadores do projeto de prevenção, aplicando-o diretamente com os alunos e seus familiares na comunidade escolar.

A equipe técnica do CREAS identificou que, ao compartilhar o conhecimento adquirido pela práxis profissional, o trabalho de prevenção poderia ser mais efetivo, e com isso atingiria a um maior número de crianças e pais, tendo em vista que "a violência por abuso sexual é mais difícil de ser identificada por não apresentar, na maioria dos casos, marcas físicas. Capacitar profissionais envolvidos com a questão talvez possa garantir a identificação precoce de vítimas" (Brino \& Williams, 2003, p. 1).

Todo o processo de construção, planejamento e execução do projeto foi realizado de forma intersetorial com os profissionais da rede de proteção, envolvendo representantes do CREAS, Educação Infantil e Ambulatório Sentinela.

Os conteúdos das capacitações foram então distribuídos em dois encontros. No primeiro encontro foram repassadas as estatísticas sobre violência sexual infantil; abordadas as definições e tipos de abuso sexual; apresentadas as consequências e comportamentos observados nas crianças vítimas de violência sexual; compreendidas as legislações vigentes sobre o tema; abordadas as orientações quanto à atuação dos profissionais de ensino quando perceberem suposta situação de violação de direitos à criança e discutida a articulação com a rede de proteção e serviços existentes no município.

No segundo encontro foram abordadas as características e objetivos da ação preventiva, sendo apresentados recursos para trabalhar a autoproteção das crianças no ambiente escolar e fornecidos tópicos para a atuação com os pais para fortalecer o papel parental. Dentre os materiais disponibilizados para o trabalho preventivo, destacam-se livros didáticos, vídeos, dinâmicas e uma cartilha de trabalho preventivo, produzida pelos profissionais do município de São José dos Pinhais/PR.

As capacitações foram realizadas no período de junho a outubro do ano de 2018, com um total de 234 (duzentos e trinta e quatro) profissionais da educação, abrangendo educadores de todos os Centros Municipais de Educação Infantil (CMEIs) de São José dos Pinhais/PR. Nesse sentido, a presente pesquisa analisou a relevância do trabalho de prevenção à violência sexual na primeira infância na articulação intersetorial das políticas de Educação, Saúde e Assistência Social do município citado acima.

\section{Metodologia}

Por tratar-se de pesquisa envolvendo seres humanos, o projeto de pesquisa que seguiu este artigo foi submetido para apreciação em comitê de ética designado, sendo aprovado sob registro CAAE: 31048120.0.0000.0101, validando sua aplicabilidade no ano de 2020.

A pesquisa aborda sobre a prevenção ao abuso sexual na primeira infância, demanda a qual está inserida na práxis da realidade social da população atendida pela rede de proteção do município de São José dos Pinhais/PR. Sendo assim, a pesquisa foi baseada no estudo das opiniões subjetivas dos profissionais da educação que participaram das capacitações realizadas de forma intersetorial no município sobre a temática em questão. 
Fundamental registrar que a análise dos dados obtidos foi realizada pelo método qualitativo, visto que esse método auxilia "no trabalho de construção do objeto estudado, facilita a descoberta de dimensões não conhecidas do problema e permite também formular e comprovar novas hipóteses" (Serapioni, 2000, p. 190). Flick (2009, p. 21) destaca que em abordagens qualitativas "em vez de partir de teorias e testá-las, são necessários 'conceitos sensibilizantes' para a abordagem dos contextos sociais a serem estudados".

Além disso, as pesquisas qualitativas reforçam o cunho social porque os estudos não se resumem a simples variáveis, "portanto, os campos de estudo não são situações artificiais criadas em laboratório, mas sim práticas e interações dos sujeitos na vida cotidiana" (Flick, 2009, p. 24). Seguindo a mesma linha de raciocínio de Flick, Sampieri (2013, p. 376) define que a pesquisa qualitativa procura "compreender e aprofundar os fenômenos, que são explorados a partir dos participantes em um ambiente natural e em relação ao contexto".

Para o desenvolvimento deste estudo, a organização metodológica se deu por meio dos seguintes instrumentos: organização e identificação de questionários e posterior análise das informações prestadas pelos profissionais capacitados da rede de educação de São José dos Pinhais/PR no período de junho a outubro de 2018, contidas no banco de dados do CREAS. Nesse banco de dados, encontram-se os questionários anônimos de satisfação em relação às capacitações desenvolvidas, os quais foram fornecidos aos profissionais da educação que participaram das capacitações. Estes questionários continham perguntas estruturadas e semiestruturadas e não possuíam qualquer tipo de identificação dos profissionais que responderam.

Os questionários consistiam em 6 (seis) perguntas fechadas para avaliar o formato e as condições dos encontros, e 5 (cinco) perguntas abertas com o intuito de obter dados sobre a perspectiva dos profissionais quanto às capacitações realizadas e a relevância para a sua atuação, além de sugestões e críticas para o aprimoramento dos encontros. Para fins deste estudo, foram analisadas 99 (noventa e nove) respostas referentes às seguintes perguntas abertas: "O conteúdo apresentado contribuiu para a sua prática profissional? Justifique" e "Você aplicaria esse projeto no seu local de trabalho? Justifique".

Pereira et al (2018, p. 67) conceitua que "os métodos qualitativos são aqueles nos quais é importante a interpretação por parte do pesquisador com suas opiniões sobre o fenômeno em estudo. Neles a coleta de dados muitas vezes ocorre por meio de entrevistas com questões abertas." Como foram utilizadas perguntas abertas na elaboração dos questionários, as respostas forneceram informações ricas para a análise de como a instituição de ensino se percebe no processo de prevenção às situações de violência sexual na primeira infância, além da relevância da articulação intersetorial para um trabalho de prevenção efetivo.

\section{Resultados e Discussão}

Ao analisar as respostas de 99 (noventa e nove) questionários do banco de dados do projeto de prevenção de violência sexual na primeira infância, realizado pelo CREAS de São José dos Pinhais/PR, notou-se que 92 (noventa e dois) profissionais que responderam à questão: "O conteúdo apresentado contribuiu para a sua prática profissional? Justifique" afirmaram que as capacitações realizadas forneceram subsídios para a prática de atividades preventivas sobre o abuso sexual na primeira infância no ambiente escolar, e ainda forneceram estratégias para lidar com as situações que envolvem essa modalidade de violência.

Ao verificar esse resultado, percebe-se que a escola está compreendendo a importância de se envolver nas questões sociais dos alunos para além das atividades curriculares. Um dos profissionais que respondeu ao questionamento referente ao conteúdo apresentado na capacitação afirmou que "Toda informação é bem-vinda, às vezes não sabemos lidar com determinadas situações e sempre precisamos de orientação" (Profissional A). Outro profissional relatou que já presenciou situações de violência no âmbito escolar: "Sim, já que foi presenciado [sic] alguns dos acontecimentos citados" (Profissional B, grifo nosso).

Diante dos relatos apresentados podemos compreender que os profissionais de educação demonstraram entender que os problemas sociais adentram o ambiente escolar e interferem na dinâmica de ensino, porém não se sentem preparados para lidar com as demandas impostas. Essa análise corrobora com a literatura que afirma: 
Almejar uma sociedade mais justa, saudável e menos violenta, onde todos sejam respeitados como cidadãos, requer repensarmos as nossas ações e as ações do Estado. Acreditamos, também, que, principalmente por sermos profissionais envolvidos no meio educacional, queiramos ou não, os problemas sociais perpassam a instituição escolar, a qual nem sempre está preparada para recebê-los. (Ribeiro \& Martins, 2011, p.26).

Os relatos dos profissionais capacitados enrijecem a importância e responsabilidade das instituições de ensino diante das situações de violência sexual infantil. Essa afirmativa pode ser observada na resposta de um dos profissionais que fez a seguinte análise sobre a violência contra crianças: "Nós professores/educadores, por muitas vezes, somos os primeiros indicadores de situações-problemas como esta” (Profissional A). Outro profissional também reforçou essa questão com a seguinte afirmação sobre a capacitação: "Faz com que percebamos a nossa responsabilidade e o quanto podemos contribuir para os cuidados com as crianças" (Profissional C).

Diante da análise dos relatos dos profissionais da educação, observa-se que eles percebem a importância de compreender os sinais que as crianças apresentam na escola e que poderiam significar vivências de situações de violência. Nesse sentido, a capacitação veio ao encontro dessa problemática, a fim de fornecer subsídios para esses profissionais.

Segundo os especialistas Ribeiro e Martins (2011, p. 98), “As consequências da violência doméstica manifestam-se, principalmente, no ambiente escolar, na forma de indisciplina, revoltas, agressões aos colegas e professores, perda de confiança, entre outros fatores", como é possível observar no relato de um dos profissionais participantes do projeto: "Despertou a minha atenção para que eu observe as mudanças de comportamento das crianças e que eu possa agir de forma adequada, auxiliando na identificação, encaminhamentos e na prevenção” (Profissional D).

Sendo assim, as consequências da violência interferem na criança em todos os aspectos da sua vida, e a escola, quando preparada para identificar e intervir nessas situações, poderá contribuir para romper e proteger as crianças das situações de violência que vivenciam.

Percebe-se que o ambiente escolar é propício para um trabalho sistemático na busca da proteção das crianças na primeira infância, pois os educadores exercem um papel importante na identificação precoce de possíveis situações de abuso, visto que “esses trabalhadores têm contato diário com as crianças e adolescentes no contexto escolar, que é um local muito propício para discussão e reflexão" (Rispens; Aleman \& Goudena, 1997, p. 121, citado por Pelisoli \& Piccoloto, 2010).

A escola então exerce grande influência na vida das crianças e suas famílias, portanto se os educadores compreenderem a realidade em que a criança está inserida, e a partir das capacitações realizadas adquirirem ferramentas para intervir nas situações de violência, estarão aptos a atuar no processo de mudança do papel da escola em busca da proteção integral das crianças.

A afirmação supracitada fica evidente nos relatos dos profissionais sobre o conteúdo adquirido nas capacitações realizadas, tais como "A partir daquilo que foi falado procurei atentar-me melhor e também pude trabalhar o tema com as crianças com mais ênfase” (Profissional C); “Agora posso ficar mais atenta e analisar uma suposta suspeita de violência” (Profissional E); "A partir da capacitação posso ter um olhar mais cuidadoso e mais atenção com os meus alunos e pais [responsáveis]” (Profissional F, grifo nosso); "Muitas coisas desconhecia, tirei duvidas, foi muito esclarecedor, onde buscar ajuda, como proceder etc.” (Profissional G); “Agora tenho subsídios para abordar o tema na sala de aula” (Profissional H).

A partir disso, é possível realizar a leitura de que os profissionais perceberam a necessidade de se ter um olhar amplo do contexto escolar para além de um local de ensino-aprendizado, pois que os alunos são integrantes de uma comunidade e de configurações familiares distintas, apresentando comportamentos que, em diversos momentos, são reflexos de padrões violadores de direitos.

Nesse sentido, cabe pensar em uma política educacional em que as crianças e adolescentes sejam vistos como seres em desenvolvimento e, portanto, precisam de atenções e cuidados que, nem sempre, encontram-se nas propostas curriculares e nas ações pedagógicas das escolas. Faz-se necessário gerar mecanismos de ação e intervenção que levem professores e gestores escolares a reverem suas práticas no atendimento aos pais e alunos (Ribeiro \& Martins, 2011). 
Uma das afirmações presentes no questionário foi a de que "Com cursos desse tipo ficamos mais atentos para situações do dia a dia" (Profissional E), sendo assim nota-se a relevância de capacitação aos profissionais da educação no que diz respeito à prevenção de abuso sexual infantil, pois esses apontaram nas respostas desconhecimento sobre o tema, bem como nas intervenções possíveis em situações de abuso sexual infantil.

Percebe-se uma lacuna no conhecimento de educadores "acerca das muitas facetas do abuso sexual, além da falta de um planejamento para que questões que envolvam a violência contra a criança, em todas as suas formas - incluindo a sexual" (Brino \& Williams, 2003, p. 8).

Diante da análise das respostas, relacionando-as com a contribuição do conteúdo apresentado para a prática profissional, foi possível identificar a urgência de sensibilizar os educadores sobre a importância de capacitação e intervenção a respeito da temática da violência sexual infantil, desmistificando os tabus e os receios que essa violência gera aos profissionais da educação, o que é possível identificar por meio dos relatos: "Com o conhecimento abordado no curso ficou mais claro para mim como devo proceder diante de uma situação de abuso, e até conversar com as crianças a terem mais cuidados com seu 'corpinho' na forma de prevenção do abuso" (Profissional I, grifo nosso); "É um assunto bem difícil de tratar e com o curso pude ter ideia de como falar sobre isso" (Profissional B).

É importante destacar que 7 (sete) profissionais participantes deste projeto responderam que o conteúdo apresentado não contribuiu para seu exercício profissional, porém não descreveram os motivos que motivaram tal resposta, não sendo possível fazer uma análise destas.

No questionamento: "Você aplicaria esse projeto no seu local de trabalho? Justifique”; 88 (oitenta e oito) profissionais se manifestaram positivamente nas respostas em relação à aplicação do projeto de prevenção à violência sexual infantil, sendo que um profissional pontuou que já havia finalizado a aplicação do projeto no seu local de trabalho após receber os instrumentos necessários para as capacitações.

No relato, esse profissional citado esclareceu que a capacitação "Contribuiu, pois no projeto usamos os livros mostrados nos encontros" (Profissional J), referindo-se aos materiais audiovisuais disponibilizados como referência para o desenvolvimento do trabalho preventivo no ambiente escolar.

Ainda em relação à pergunta acima, 3 (três) profissionais responderam que estavam efetivando o projeto de prevenção, e que a comunidade estava demonstrando boa receptividade ao projeto.

Observou-se ainda que 84 (oitenta e quatro) profissionais informaram que aplicariam o projeto, porém, a grande maioria apontou como decisiva para a implantação o auxílio da equipe pedagógica, da equipe do CREAS ou em trabalho em rede com outras secretarias, ou seja, mesmo com a capacitação fornecendo conhecimento e instrumentos para o trabalho, a grande maioria optou em não executar o trabalho de prevenção de forma isolada e sem a participação dos demais integrantes da rede de proteção.

A afirmativa acima pode ser observada a partir da análise dos seguintes relatos dos entrevistados sobre aplicar ou não o projeto: "Aplicaria, mas com certeza seria necessário o apoio técnico da equipe do CREAS, para abordar assuntos tão delicados na comunidade" (Profissional L). "Creio que se a instituição auxiliar, sim” (Profissional K). "Sim, no entanto precisa de profissionais capacitados para conversar com a comunidade, pois é um tema complexo” (Profissional M, grifo nosso). "Para aplicação no CMEI [Centro Municipal de Educação Infantil] seria necessário profissionais do próprio projeto para auxiliar nas demandas que possam aparecer" (Profissional N, grifo nosso).

A partir disso, nota-se uma insegurança dos educadores em abordar atividades relativas à prevenção do abuso sexual infantil sem o auxílio de uma equipe. Essa insegurança corrobora com autores que apontam que "o desenvolvimento de atividades criativas para que se possa estar abordando a questão da violência, suas consequências para a sociedade e para os indivíduos constitui em outro desafio para muitos educadores" (Njaine \& Minayo, 2003, p. 132). 
Observa-se que os profissionais que responderam que não aplicariam o projeto de prevenção ao abuso sexual demonstraram medos e inseguranças para trabalhar com a temática. Um dos profissionais relatou que "Não, algumas brincadeiras lúdicas sim, conversação a determinado assunto, não" (Profissional K). Ou seja, o profissional demonstrou que aplicaria alguns dos instrumentais lúdicos visando o trabalho com prevenção, porém demonstrou insegurança em dialogar com as crianças sobre os aspectos da prevenção ao abuso sexual infantil. Outro profissional ainda afirmou que "Amei o projeto, amei tudo o que foi apresentado, porém [...] eu precisaria de mais suporte [...]" (Profissional L, grifo nosso).

Nesse sentido, é necessário um trabalho contínuo de sensibilização com os profissionais da educação para perceberem a necessidade de se qualificarem sobre a temática e criarem segurança para execução de atividades capazes de trabalhar a prevenção da violência sexual infantil no âmbito escolar.

As atitudes de ruptura de preconceitos, medos e silêncios de alguns professores diante do conhecimento de situações graves de violência envolvendo os alunos demonstraram o potencial transformador da escola no sentido de ampliar o diálogo sobre essa questão, diminuindo as distâncias entre educador-educando (Njaine \& Minayo, 2003).

Apesar das dificuldades apontadas pelos educadores, é possível verificar que alguns profissionais já estão tomando atitudes para romper esse medo por meio de estratégias para lidar com essa questão desafiadora que é a violência sexual infantil. Isso pode ser observado nos relatos dos profissionais que afirmaram que aplicariam o projeto: "Para poder entender e ajudar as crianças" (Profissional O); "Pois é um trabalho que necessita da interação de todos" (Profissional P); "É um assunto difícil de se tratar, mas não podemos deixar no esquecimento" (Profissional Q).

Percebe-se então que para a superação de tais obstáculos faz-se necessária a promoção de capacitações continuadas dos profissionais da rede de ensino, visando a articulação intersetorial com os demais serviços da rede de proteção.

Diante disso, reforçamos a importância da formação continuada dos professores, como uma das tentativas de sensibilização para uma melhor compreensão pelos educadores dos problemas presentes no cotidiano escolar, que apresentam as crianças vitimizadas (Ribeiro \& Martins, 2011).

É notório que o projeto executado foi incipiente para despertar a reflexão sobre a importância do trabalho de prevenção à violência sexual na primeira infância de forma intersetorial. Porém, ao analisar os questionários, percebe-se a necessidade de manter intervenções intersetoriais com o desígnio de sensibilizar a escola para transpassar as grades curriculares e compreender a necessidade de promover atividades interventivas preventivas diante da realidade social dos alunos, especificamente, da violência sexual.

\section{Considerações Finais}

A partir de tal estudo, considera-se urgente e necessária a difusão de informações sobre a prevenção da violência sexual infantil por meio de capacitações aos profissionais das instituições de ensino, pois notou-se amplo desconhecimento e insegurança sobre o assunto.

Nesse sentido, como sugestão para abordagens futuras sobre a temática abordada, observa-se a necessidade de que a prevenção ao abuso sexual na primeira infância seja incluído em currículos escolares e abordado em cursos de capacitações profissionais, pois a informação e a prevenção podem contribuir com a proteção de diversas crianças de nossa sociedade.

Ao encontro dessa problemática, os questionários demonstraram que as capacitações realizadas forneceram estratégias e subsídios aos profissionais para a prática de atividades preventivas sobre a violência sexual na primeira infância no ambiente escolar.

Por meio da análise dos dados foi possível avaliar a relevância da articulação intersetorial na prevenção da violência sexual infantil. Nota-se que os olhares das diferentes áreas de conhecimento se complementam, viabilizando um trabalho multidisciplinar interventivo no processo de rompimento das situações de violências. 
Por fim, destaca-se que o projeto executado pelo CREAS de São José dos Pinhais/PR é um exemplo interventivo passível de ser multiplicado pelos demais equipamentos no âmbito da proteção social, e este demonstra-se relevante, uma vez que a prevenção é a principal ação na busca da garantia da proteção das crianças diante da violência sexual na primeira infância.

\section{Agradecimentos}

Agradecemos as equipes técnicas do PAEFI - CREAS de São José dos Pinhais/PR, aos profissionais do Ambulatório Sentinela e da Secretaria Municipal de Educação Infantil que participaram do planejamento e viabilizaram a aplicação deste projeto no município. Ainda, agradecemos a Secretaria Municipal de Assistência Social de São José dos Pinhais/PR que permitiu que essas servidoras efetivassem a pesquisa que culminou na produção deste artigo.

\section{Referências}

Brasil. (1988). Constituição da República Federativa do Brasil. Brasília, DF: Senado Federal.

Brasil. (2003). Estatuto da Criança e do Adolescente de 1990. (4a ed.), Brasília, DF.

Brasil. (2004). Ministério da Educação. Secretaria de Educação Infantil e Fundamental. Política Nacional de Educação Infantil: pelos direitos das crianças de O a 6 anos à educação. Brasília, DF.

Brasil. (2011). Ministério do Desenvolvimento Social e Combate à Fome - MDS. Secretaria Nacional de Assistência Social. Orientações técnicas: Centro de Referência Especializado de Assistência Social - CREAS. Brasília, DF.

Brasil. (2009). Ministério do Desenvolvimento Social e Combate à Fome - MDS. Secretaria Nacional de Assistência Social. Tipificação nacional de serviço socioassistencial. Brasília, DF.

Brasil. (2016). Presidência da República. Lei n.13.257, de 08 de março de 2016. Políticas públicas para a primeira infância. Brasília, DF. http://www.planalto.gov.br/ccivil_03/_ato2015-2018/2016/lei/L13257.htm.

Brino, R. F. \& Williams, L. C. A. (2003). Capacitação do educador acerca do abuso sexual infantil. Interação em Psicologia, 7(2), 1-10.

Flick, U. (2009). Desenho da pesquisa qualitativa. Artmed.

Njaine, K. \& Minayo, M. C. S. (2003). Violência na escola: identificando pistas para a prevenção. Interface-Comunic., Saúde, Educ., 7(.13), 19-34. http://www.scielo.br/pdf/icse/v7n13/v7n13a08.pdf.

Pelisoli, C. \& Piccoloto, L. B. (2010). Prevenção do abuso sexual infantil: estratégias cognitivo-comportamentais na escola, na família e na comunidade. Rev. bras. ter. cogn., Rio de Janeiro, 6(1), 108-137. http://pepsic.bvsalud.org/scielo.php?script=sci_arttext\&pid=S180856872010000100007\&lng=pt\&nrm=iso.

Pereira A. S. et al. (2018). Metodologia da pesquisa científica. UAB/NTE/UFSM. https://repositorio.ufsm.br/bitstream/handle/1/15824/Lic_ Computacao_Metodologia-Pesquisa-Cientifica.pdf?sequence=1.

Ribeiro, M. M. \& Martins, R. B. (2011). Violência doméstica contra a criança e o adolescente: a realidade velada e desvelada do ambiente escolar. Curitiba: Juruá.

Sampieri, R. H. (2013). Metodologia de pesquisa. Penso.

Serapioni, M. (2000). Métodos qualitativos e quantitativos na pesquisa social em saúde: algumas estratégias para a integração. Ciênc. Saúde coletiva, Rio de Janeiro, 5(1), 187-192. http://www.scielo.br/scielo.php?script=sci_arttext\&pid=S1413-81232000000100016\&lng=en\&nrm=iso.

World Health Organization. (1999). Consultation on child abuse prevention. Geneva: World Health Organization. 